\title{
Role of TLR4/NADPH oxidase/ROS-activated p38 MAPK in VCAM-1 expression induced by lipopolysaccharide in human renal mesangial cells
}

I-Ta Lee ${ }^{1+}$, Ruey-Horng Shih" ${ }^{2 \dagger}$, Chih-Chung Lin ${ }^{1}$, Jung-Tsan Chen ${ }^{2}$ and Chuen-Mao Yang ${ }^{2^{*}}$

\begin{abstract}
Background: In bacteria-induced glomerulonephritis, Toll-like receptor 4 (TLR4) activation by lipopolysaccharide (LPS, a key component of the outer membranes of Gram-negative bacteria) can increase oxidative stress and the expression of vascular cell adhesion molecule-1 (VCAM-1), which recruits leukocytes to the glomerular mesangium. However, the mechanisms underlying VCAM-1 expression induced by LPS are still unclear in human renal mesangial cells (HRMCs).

Results: We demonstrated that LPS induced VCAM-1 mRNA and protein levels associated with an increase in the promoter activity of VCAM-1, determined by Western blot, RT-PCR, and promoter assay. LPS-induced responses were inhibited by transfection with siRNAs of TLR4, myeloid differentiation factor 88 (MyD88), Nox2, Nox4, p47 ${ }^{\text {phox }}$, c-Src, p38 MAPK, activating transcription factor 2 (ATF2), and p300 or pretreatment with the inhibitors of reactive oxygen species (ROS, edaravone), NADPH oxidase [apocynin (APO) or diphenyleneiodonium chloride (DPI)], c-Src (PP1), p38 MAPK (SB202190), and p300 (GR343). LPS induced NADPH oxidase activation, ROS production, and p4 $7^{\text {phox }}$ translocation from the cytosol to the membrane, which were reduced by PP1 or c-Src siRNA. We observed that LPS induced TLR4, MyD88, c-Src, and p47 ${ }^{\text {phox }}$ complex formation determined by co-immunoprecipitation and Western blot. We further demonstrated that LPS stimulated ATF2 and p300 phosphorylation and complex formation via a c-Src/NADPH oxidase/ROS/p38 MAPK pathway. Up-regulation of VCAM-1 led to enhancing monocyte adhesion to HRMCs challenged with LPS, which was inhibited by siRNAs of c-Src, p47 ${ }^{\text {phox }}$, p38 MAPK, ATF2, and p300 or pretreatment with an anti-VCAM-1 neutralizing antibody.

Conclusions: In HRMCs, LPS-induced VCAM-1 expression was, at least in part, mediated through a TLR4/MyD88/ c-Src/NADPH oxidase/ROS/p38 MAPK-dependent p300 and ATF2 pathway associated with recruitment of monocyte adhesion to kidney. Blockade of these pathways may reduce monocyte adhesion via VCAM-1 suppression and attenuation of the inflammatory responses in renal diseases.
\end{abstract}

Keywords: Lipopolysaccharide, Vascular cell adhesion molecule-1, Toll-like receptors, Reactive oxygen species, NADPH oxidase

\footnotetext{
* Correspondence: chuenmao@mail.cgu.edu.tw

${ }^{\dagger}$ Equal contributors

2Department of Physiology and Pharmacology and Health Aging Research Center, College of Medicine, Chang Gung University, 259 Wen-Hwa 1st Road, Kwei-San, Tao-Yuan, Taiwan

Full list of author information is available at the end of the article
} 


\section{Background}

Mesangial cells (MCs) response to various pathological stimuli associated with the main events of glomerular inflammation, including leukocyte infiltration, cell proliferation, and fibrosis, which were predominantly mediated through induction of adhesion molecules [1,2]. In bacteria-induced glomerulonephritis, lipopolysaccharide (LPS, a key component of the outer membranes of Gramnegative bacteria) stimulated VCAM-1 induction in the murine glomerular mesangium [3]. It has been also reported that Toll-like receptor 4 (TLR4) activation by LPS increased the expression of adhesion molecules, such as VCAM-1 which recruits leucocytes to the kidney $[4,5]$.

Reactive oxygen species (ROS) are known to play a prominent role in the pathogenesis of various renal disorders, such as nephropathy [6], renal ischemia [7], and renal fibrosis [8]. Nicotinamide adenine dinucleotide phosphate (NADPH) oxidase is an important enzymatic source for the production of ROS under various pathologic conditions [9]. NADPH oxidase-derived ROS have been shown to induce monocyte chemoattractant protein1 expression in MCs leading to nephropathy [10]. Activated NADPH oxidase is a multimeric protein complex, including $\mathrm{p} 47^{\text {phox }}$ cytosolic subunits. It has been shown that the phosphorylation of $\mathrm{p} 47^{\text {phox }}$ results in its membrane translocation and activation of NADPH oxidase [11]. It has been reported that ROS generation is necessary for VCAM-1 induction in IL- $1 \beta$-treated human tracheal smooth muscle cells [12]. The role of ROS in mediating VCAM-1 expression induced by LPS remains to be clarified in human renal mesangial cells (HRMCs).

Src family kinases have been shown to mediate NADPH oxidase activation and ROS generation in lung endothelial cells [13]. c-Src has also been shown to stimulate the phosphorylation of $\mathrm{p} 47^{\text {phox }}$ and therefore increased NADPH oxidase-derived ROS in VCAM-1 expression in IL-1 $\beta$-treated human tracheal smooth muscle cells [12]. However, the mechanisms underlying NADPH oxidase activation and ROS production regulated by $\mathrm{p} 47^{\text {phox }}$ translocation mediated through c-Src in LPS-induced VCAM1 expression are also unclear in HRMCs. On the other hand, it has also been shown that ROS stimulate p38 MAPK phosphorylation in opossum kidney cells [14]. However, the role of p38 MAPK in NADPH oxidasederived ROS-dependent VCAM-1 expression induced by LPS is still unclear in HRMCs.

The promoter region of VCAM-1 possesses a series of functional element, including activator protein-1 (AP-1) binding sites that are essential for induction of VCAM-1 associated with inflammatory responses [15]. It has been established that various stimuli, such as bacterial infections have been shown to induce AP-1 activity [16]. AP-1 is a dimeric protein, consisting of dimers composed of members of either ATF, Jun, or Fos families of proteins
[17]. However, the role of ATF2 in LPS-induced VCAM-1 expression is still unknown in HRMCs.

In addressing these questions, experiments were undertaken to investigate the mechanisms underlying LPSinduced VCAM-1 expression mediated through NADPH oxidase activation/ROS generation in HRMCs. These findings suggest that in HRMCs, LPS-induced VCAM-1 expression was, at least in part, mediated through a TLR4/ MyD88/c-Src/NADPH oxidase/ROS/p38 MAPK-dependent p300 and ATF2 pathway relevant to recruitment of monocyte adhesion to kidney. These results provide new insights into the mechanisms of LPS action on HRMCs to regulate the expression of VCAM-1 and thus exaggerates the inflammatory responses.

\section{Results}

\section{LPS induces VCAM- 1 expression via a} TLR4/MyD88-dependent pathway

To investigate the effects of LPS on VCAM-1 expression, HRMCs were treated with various concentrations of LPS $(100,10,1$, and $0.1 \mu \mathrm{g} / \mathrm{ml})$. As shown in Figure 1A, LPS markedly induced VCAM-1 expression in a time- and concentration-dependent manner in HRMCs. TLR4 is an essential signaling receptor for LPS [18]. Indeed, we also demonstrated that LPS-induced VCAM-1 expression was inhibited by transfection with TLR4 siRNA, but not TLR2 siRNA in HRMCs (Figure 1B). In addition, LPS-induced VCAM-1 promoter activity was also reduced by transfection with TLR4 siRNA (Figure 1C). On the other hand, we demonstrated that LPS could directly induce TLR4 mRNA expression in a time-dependent manner in HRMCs (Figure 1D). The TLR4 signaling cascade initiated following LPS binding is enhanced by homodimerization of the receptor and subsequent recruitment of TIR domaincontaining adaptor molecules (TIRAP) to the cytoplasmic domain of the receptor [19]. These adaptors include myeloid differentiation factor 88 (MyD88), MyD88 adaptorlike protein (Mal), TIR-containing adaptor inducing IFN $\beta$ (TRIF), also known as TIRAP-1 (TICAM-1), and TRIFrelated adaptor molecule (TRAM). Activation of TLR4 leads to stimulation of both MyD88-dependent and MyD88-independent pathways [19]. Moreover, in HRMCs, we showed that LPS-induced VCAM-1 expression was inhibited by transfection with MyD88 siRNA (Figure 1E). These results suggested that LPS induced VCAM-1 expression through a TLR4/MyD88-dependent signaling pathway.

\section{LPS induces NADPH oxidase activation and ROS production in HRMCs}

$\mathrm{NADPH}$ oxidase is an important enzymatic source for the production of ROS under various pathologic conditions [9]. LPS has been shown to activate NADPH oxidase and stimulate ROS generation in human tracheal 


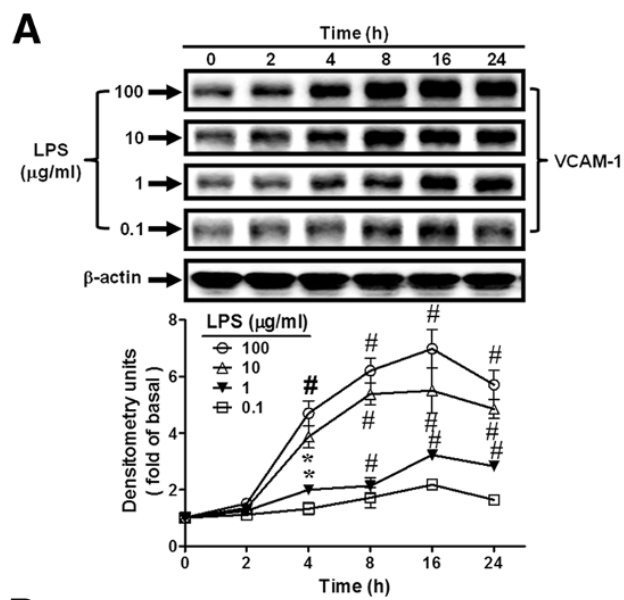

B

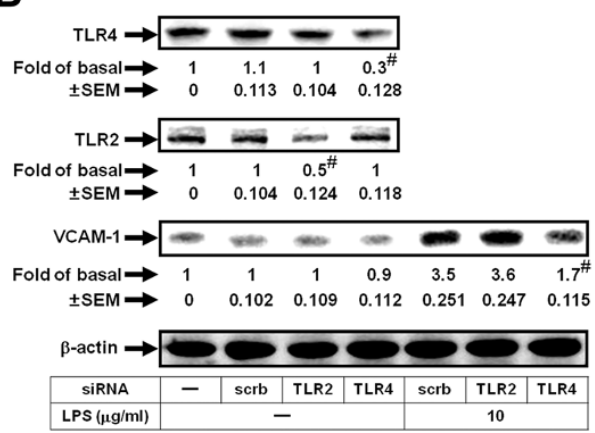

C
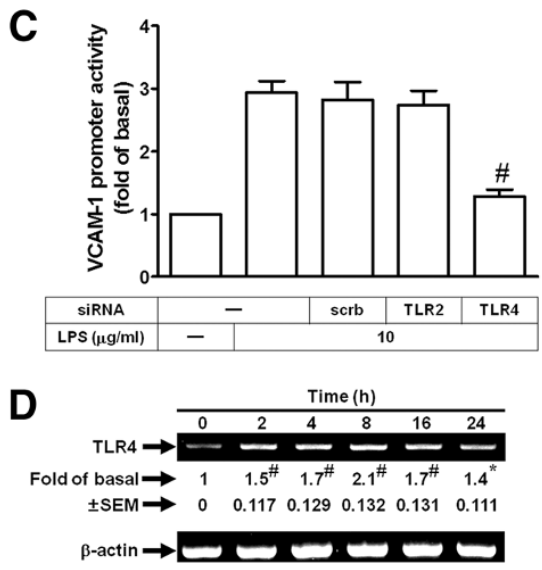

$\mathbf{E}$

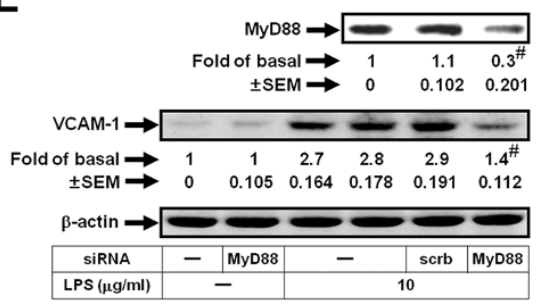

Figure 1 LPS induces VCAM-1 expression via TLR4/MyD88 in HRMCs. (A) Cells were treated with LPS for the indicated time intervals. The protein levels of VCAM-1 were determined by Western blot. (B) Cells were transfected with TLR2 siRNA, TLR4 siRNA, or scrambled siRNA, and then incubated with LPS $(10 \mu \mathrm{g} / \mathrm{ml})$ for $8 \mathrm{~h}$. The levels of TLR4, TLR2, and VCAM-1 protein were determined by Western blot. (C) Cells were transiently transfected with VCAM-1-luc reporter gene and TLR2 siRNA, TLR4 siRNA, or scrambled siRNA, and then incubated with LPS for $6 \mathrm{~h}$. The VCAM-1 promoter activity was determined in the cell lysates. (D) Cells were incubated with LPS (10 $\mu \mathrm{g} / \mathrm{ml})$ for the indicated time intervals. The mRNA expression of TLR4 was determined by RT-PCR. (E) Cells were transfected with MyD88 siRNA or scrambled siRNA, and then incubated with LPS $(10 \mu \mathrm{g} / \mathrm{ml})$ for $8 \mathrm{~h}$. The levels of MyD88 and VCAM-1 protein were determined by Western blot. All figures are representative of three independent experiments, performed in duplicate or triplicate. Data are expressed as means \pm SEM. ${ }^{*} P<0.05 ;{ }^{\#} P<0.01$, as compared with the cells exposed to vehicle alone $(\mathbf{A}, \mathbf{D}) .{ }^{\#} P<0.01$, as compared with the cells exposed to scrambled siRNA alone [B (upper panel), $\mathbf{E}$ (upper panel)] or LPS + scrambled siRNA [B (lower panel), C, E (lower panel)].

smooth muscle cells [18]. Here, we investigated whether LPS-induced VCAM-1 expression was mediated through NADPH oxidase/ROS. As shown in Figsure 2A and B, pretreatment with the inhibitor of $\mathrm{NADPH}$ oxidase [apocynin (APO) or diphenyleneiodonium chloride (DPI)] or a ROS scavenger (edaravone, MCI-186) markedly inhibited LPS-induced VCAM-1 protein and mRNA expression and promoter activity in HRMCs. Activated NADPH oxidase is a multimeric protein complex consisting of at least three cytosolic subunits of $\mathrm{p} 47^{\text {phox }}$, $\mathrm{p} 67^{\text {phox }}$, and $\mathrm{p} 40^{\text {phox }}$. Phosphorylation of $\mathrm{p} 47^{\text {phox }}$ leads to a conformational change allowing its interaction with p22 $2^{\text {phox }}[20]$. It has been demonstrated that $\mathrm{p} 47^{\text {phox }}$ organizes the translocation of other cytosolic factors, hence its designation as "organizer subunit" [20]. Here, we showed that transfection with $\mathrm{p} 47^{\mathrm{phox}}$ siRNA inhibited LPS-mediated VCAM-1 induction (Figure 2C). Indeed, in cultured HRMCs, Nox2, Nox4, and Nox5 were expressed (data not shown). Moreover, in this study, we also observed that transfection with siRNA of Nox2 or Nox4 markedly reduced LPS-induced VCAM-1 expression in HRMCs (Figures 2D and E). Thus, we suggested that LPS-induced ROS generation was, at least in part, mediated via Nox 2 or Nox 4 activation in these cells. We further demonstrated that LPS stimulated NADPH oxidase activation and ROS, including $\mathrm{H}_{2} \mathrm{O}_{2}$ and $\mathrm{O}_{2}^{*-}$ production in HRMCs (Figures $2 \mathrm{~F}$ and $\mathrm{G}$ ). Moreover, pretreatment with APO, DPI, or edaravone inhibited LPS-enhanced ROS generation in HRMCs (Figure 2H), suggesting that LPS stimulated ROS production via NADPH oxidase activation. We next investigated the effect of LPS on translocation of p $47^{\text {phox }}$ in HRMCs. Cells were treated with $10 \mu \mathrm{g} / \mathrm{ml}$ LPS for the indicated time intervals. The membrane and cytosolic fractions were prepared and subjected to Western blot analysis using an anti-p $47^{\text {phox }}$ antibody. As shown in Figure 2I, LPS stimulated a time-dependent increase in 
A

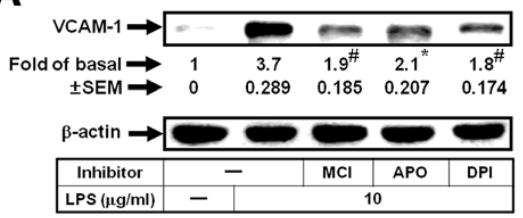

B

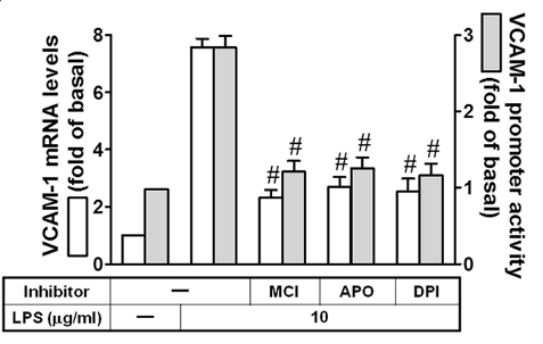

C
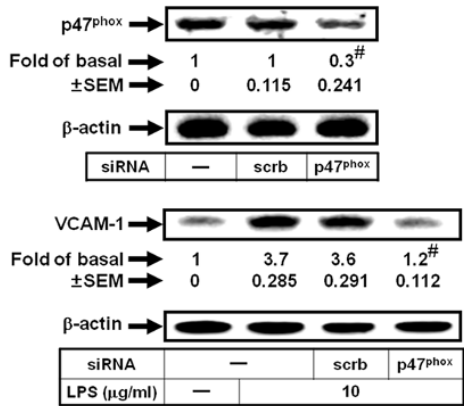

D
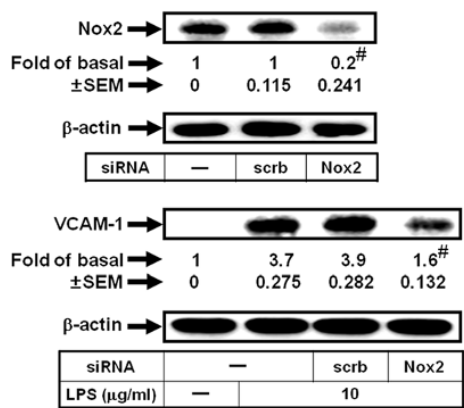

E

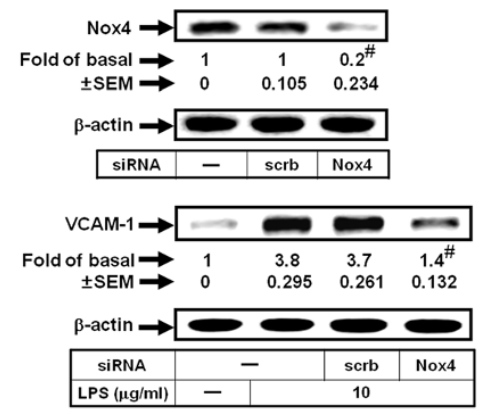

$\mathbf{F}$

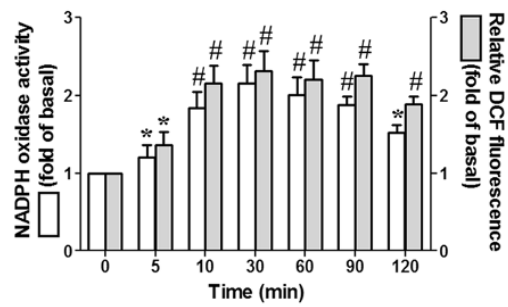

G

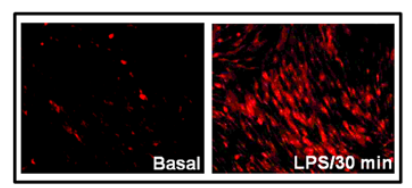

H
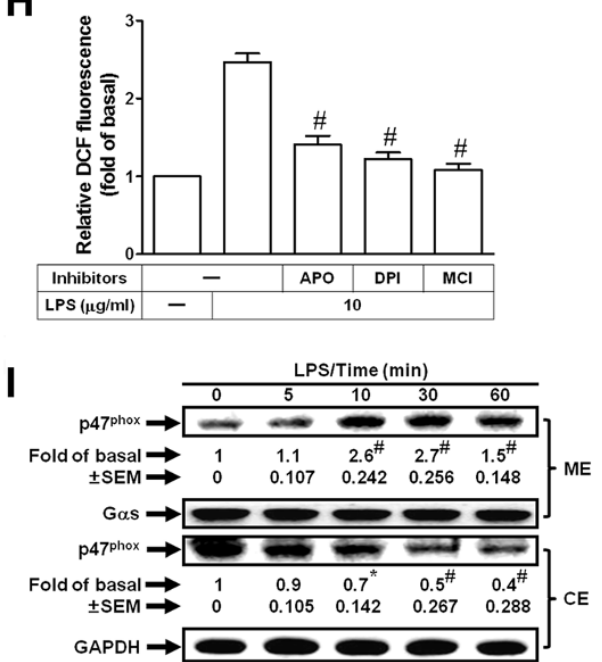

Figure 2 LPS induces VCAM-1 expression via NADPH oxidase/ROS. (A) Cells were pretreated with MCl-186 (MCl, $100 \mu M)$, APO (100 $\mu$ M), or DPI $(10 \mu \mathrm{M})$, and then incubated with LPS for $8 \mathrm{~h}$. The levels of VCAM-1 protein were determined. (B) Cells were pretreated with MCl-186 (MCI), APO, or DPI, and then incubated with LPS for $4 \mathrm{~h}$ or $6 \mathrm{~h}$. The mRNA levels and promoter activity of VCAM-1 were determined. (C, D, E) Cells were transfected with p4 ${ }^{\text {phox }}$, Nox2, Nox4, or scrambled siRNA, and then incubated with LPS for 8 h. The protein levels of p47 ${ }^{\text {phox }}$, Nox2, Nox4, and VCAM-1 were determined. (F) Cells were stimulated with LPS for the indicated times. NADPH oxidase and ROS generation were measured. (G) DHE fluorescence image after 30 min of stimulation with LPS. (H) Cells were pretreated with MCl-186 (MCl), APO, or DPI, and then treated with LPS for $30 \mathrm{~min}$. ROS generation was measured. (I) Cells were stimulated with LPS for the indicated times. The membrane and cytosolic fractions were prepared and subjected to Western blot using an anti-p47 $7^{\text {phox }}$ antibody. Gsa and GAPDH were used as a marker protein for membrane and cytosolic fractions, respectively. All figures are representative of three independent experiments, performed in duplicate. Data are expressed as means \pm SEM. ${ }^{*} P<0.05 ;{ }^{\#} P<0.01$, as compared with the cells exposed to LPS alone $(\mathbf{A}, \mathbf{B}, \mathbf{H})$, scrambled siRNA alone (upper panels of $\mathbf{C}, \mathbf{D}, \mathbf{E}$ ), LPS + scrambled siRNA (lower panels of $\mathbf{C}, \mathbf{D}, \mathbf{E})$, or vehicle alone $(\mathbf{F}, \mathbf{I})$. 
translocation of $\mathrm{p} 47^{\text {phox }}$ from the cytosol to the membrane. These data demonstrated that LPS induced ROS generation through a NADPH oxidase-dependent signaling leading to VCAM-1 expression in HRMCs.

\section{LPS enhances NADPH oxidase activation and ROS generation via c-Src in HRMCs}

Recent studies have shown that TLR4 signaling is coupled to c-Src family kinase activation, tyrosine phosphorylation of zonula adherens proteins, and opening of the paracellular pathway in human lung microvascular endothelia $[21,22]$. We investigated whether c-Src was involved in the induction of VCAM-1 in response to LPS. As shown in Figures $3 \mathrm{~A}$ and $\mathrm{B}$, pretreatment with the inhibitor of $\mathrm{c}-\mathrm{Src}$ (PP1) reduced LPS-induced VCAM-1 protein and mRNA expression and promoter activity. In addition, transfection with c-Src siRNA also inhibited LPS-induced VCAM-1 expression (Figure 3C). LPS could stimulate c-Src phosphorylation, which was inhibited by pretreatment with PP1 (Figure 3D). c-Src has been shown to regulate ROS generation in human tracheal smooth muscle cells [9]. Moreover, we also found that LPS-induced $\mathrm{p} 47^{\text {phox }}$ translocation, NADPH oxidase activation, and ROS generation were inhibited by transfection with c-Src siRNA (Figures 3E and F). We further investigated the physical association of TLR4, c-Src, and $\mathrm{p} 47^{\text {phox }}$ in LPS-induced ROS generation and VCAM-1 expression. As shown in Figure $3 \mathrm{G}$, the protein levels of TLR4 and $\mathrm{p} 47^{\text {phox }}$ were time-dependently increased in c-Src-immunoprecipitated complex in LPS-treated HRMCs. Thus, these data suggested that LPS-induced VCAM-1 expression is mediated through c-Src-dependent NADPH oxidase/ROS generation in HRMCs

\section{LPS induces VCAM-1 expression via NADPH oxidase/ ROS-dependent p38 MAPK activation in HRMCs}

MAPKs, including p38 MAPK, JNK1/2, and p42/p44 MAPK have been shown to regulate VCAM-1 induction in various cell types [20,23-25]. Here, we determined whether these three MAPKs were involved in LPS-induced VCAM1 expression in HRMCs. As shown in Figures 4A and B, pretreatment with the inhibitor of p38 MAPK (SB202190), JNK1/2 (SP600125), or MEK1/2 (U0126) markedly inhibited LPS-induced VCAM-1 protein and mRNA expression and promoter activity in HRMCs. It has been shown that ROS-dependent activation of MAPKs is required for inflammatory responses [26-28]. In HRMCs, LPS-stimulated p38 MAPK phosphorylation was inhibited by transfection with either $\mathrm{c}$-Src siRNA or $\mathrm{p} 47^{\text {phox }}$ siRNA (Figure $4 \mathrm{C}$ ). However, pretreatment with PP1, but not edaravone inhibited LPS-induced p42/p44 MAPK and JNK1/2 phosphorylation (Figures 4D and E). Finally, the involvement of p38 MAPK in LPS-induced VCAM-1 expression was further confirmed by transfection with p38 MAPK siRNA. As shown in Figure 4F, transfection with p38 siRNA reduced the expression of total p38 MAPK protein and subsequently attenuated VCAM-1 expression induced by LPS. These results indicated that $\mathrm{p} 38 \mathrm{MAPK}$ phosphorylation involved in VCAM-1 induction by LPS was mediated through a cSrc/NADPH oxidase/ROS-dependent cascade in HRMCs.

\section{LPS induces VCAM-1 expression via p38 MAPK-dependent ATF2 activation}

ATF2 is activated by inflammatory signals transduced by the p38 MAPK pathway [29]. In addition, LPS has also been shown to regulate VCAM-1 expression via an ATF2 signaling [30]. In this study, we investigated whether ATF2 activation was involved in LPS-induced VCAM-1 expression in HRMCs. As shown in Figures 5A, B and C, transfection with ATF2 siRNA inhibited LPS-induced VCAM-1 protein and mRNA expression and promoter activity in HRMCs. On the other hand, we demonstrated that LPS time-dependently stimulated ATF2 phosphorylation, which was inhibited by transfection with siRNA of c-Src, p47 ${ }^{\text {phox }}$, or p38 MAPK in HRMCs (Figures 5D and E). We found that LPS induced ATF2 translocation from the cytosol to the nucleus, which was inhibited by pretreatment with either PP1 or edaravone (MCI-186) (Figure 5F). These data suggested that ATF2 phosphorylation involved in LPS-induced VCAM-1 expression is mediated through cSrc/NADPH oxidase/ROS/p38 MAPK pathway in HRMCs.

\section{LPS induces VCAM-1 expression via the formation of an ATF2/p300 complex}

p300 has been shown to be involved in VCAM-1 induction [12]. Here, we investigated whether LPS could induce VCAM-1 expression via p300 in HRMCs. As shown in Figures $6 \mathrm{~A}, \mathrm{~B}$ and $\mathrm{C}$, pretreatment with the inhibitor of p300 (GR343) significantly reduced LPS-induced VCAM-1 protein and mRNA expression and promoter activity. On the other hand, we also demonstrated that transfection with p300 siRNA down-regulated p300 protein levels and LPSinduced VCAM-1 expression (Figure 6D). LPS also stimulated p300 phosphorylation in a time-dependent manner in HRMCs, which was inhibited by pretreatment with GR343, PP1, edaravone (MCI-186), apocynin, or SB202190 (Figures 6E and F). We further investigated the physical association between p300 and ATF2 in LPS-treated HRMCs. As shown in Figure 6G, cells were stimulated with $10 \mu \mathrm{g} / \mathrm{ml}$ LPS for the indicated time intervals. The cell lysates were subjected to immunoprecipitation using an anti-p300 antibody, and then the immunoprecipitates were analyzed by Western blotting using an anti-p300 or anti-ATF2 antibody. The protein levels of ATF2 were time-dependently increased in p300-immunoprecipitated complex. These results suggested that LPS triggered the interaction between p300 and ATF2 leading to VCAM-1 expression in HRMCs. 
A

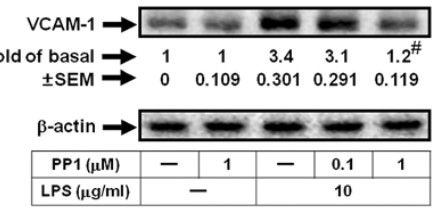

B

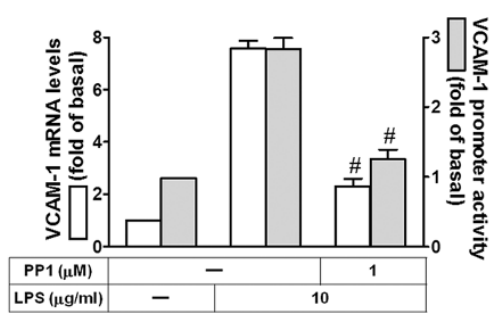

C
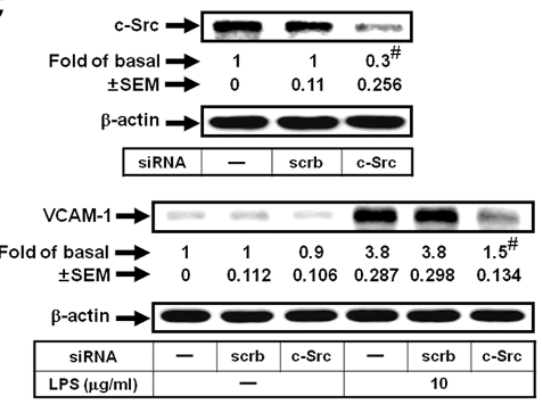

D

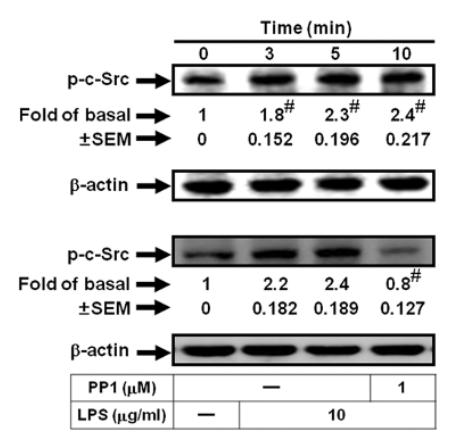

E

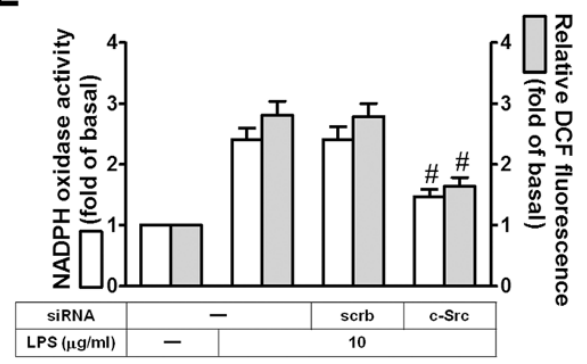

$\mathbf{F}$

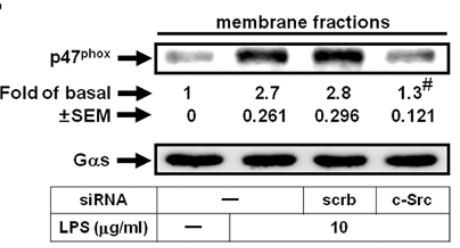

G

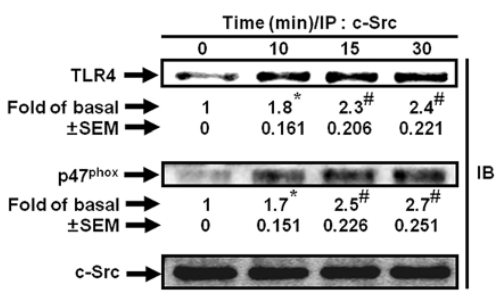

Figure 3 LPS induces VCAM-1 expression via c-Src. (A) Cells were pretreated with PP1, and then incubated with LPS for 8 h. VCAM-1 protein levels were determined. (B) Cells were pretreated with PP1, and then incubated with LPS for $4 \mathrm{~h}$ or $6 \mathrm{~h}$. The mRNA levels and promoter activity of VCAM-1 were determined. (C) Cells were transfected with c-Src siRNA, and then incubated with LPS for $8 \mathrm{~h}$. The protein levels of c-Src and VCAM-1 were determined. (D) Cells were pretreated without or with PP1 $(1 \mu \mathrm{M})$, and then treated with LPS for the indicated times or 10 min. The expression of phospho-c-Src was determined. (E) Cells were transfected with c-Src siRNA, and then stimulated with LPS for 30 min. The NADPH oxidase activity and ROS generation were determined. (F) Cells were transfected with c-Src siRNA, and then incubated with LPS for 30 min. The membrane fractions were prepared and subjected to Western blot using an anti-p47 $7^{\text {phox }}$ antibody. (G) Cells were treated with LPS for the indicated times. The cell lysates were subjected to immunoprecipitation using an anti-c-Src antibody, and then the immunoprecipitates were analyzed by Western blot using an anti-TLR4, anti-p47 ${ }^{\text {phox }}$, or anti-c-Src antibody. All figures are representative of three independent experiments, performed in duplicate. Data are expressed as means \pm SEM. ${ }^{*} P<0.05 ;{ }^{*} P<0.01$, as compared with the cells exposed to LPS alone [A, B, D (lower panel)], scrambled siRNA alone (C, upper panel), LPS + scrambled siRNA [C (lower panel), E, F], or vehicle alone [D (upper panel), G].

Induction of VCAM-1 enhances adhesion of THP-1 cells to HRMCs challenged with LPS

We investigated the roles of $\mathrm{c}-\mathrm{Src}, \mathrm{p} 47^{\text {phox }}, \mathrm{p} 38$ MAPK, ATF2, and p300 in the adhesion of THP-1 cells to HRMCs challenged with LPS. As shown in
Figure 7, transfection with siRNAs of $\mathrm{c}-\mathrm{Src}, \mathrm{p} 47^{\text {phox }}$, p38 MAPK, ATF2, and p300 or preincubation with an anti-VCAM-1 neutralizing antibody markedly inhibited the adhesion of THP-1 cells to HRMCs treated with LPS. 
A

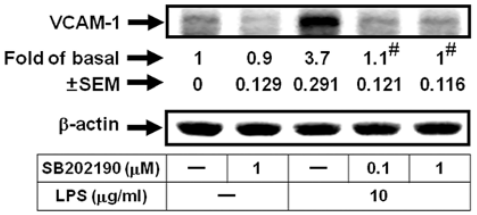

VCAM- $\rightarrow-\cdots-20$ Fold of basal $\rightarrow \begin{array}{lllll}1 & 0.9 & 3.8 & 2.7^{*} & 1.5^{\#}\end{array}$ $\pm \mathrm{SEM} \rightarrow 0 \quad 0.131 \quad 0.293 \quad 0.221 \quad 0.136$

$\beta$-actin $\rightarrow$

\begin{tabular}{|c|c|c|c|c|c|}
\hline U0126 $(\mu \mathrm{M})$ & - & 1 & - & 0.1 & 1 \\
\hline LPS $(\mu \mathrm{g} / \mathrm{ml})$ & \multicolumn{2}{|c|}{-} & \multicolumn{3}{|c|}{10} \\
\hline
\end{tabular}

VCAM- $\rightarrow=-\infty=$

Fold of basal $\rightarrow \begin{array}{lllll}1 & 0.9 & 3.6 & 1.5^{\#} & 1.4^{\#}\end{array}$ \pm SEM $\rightarrow \quad \begin{array}{lllll}0 & 0.108 & 0.273 & 0.121 & 0.126\end{array}$

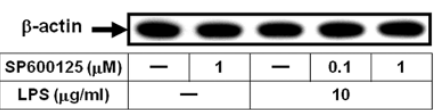

B

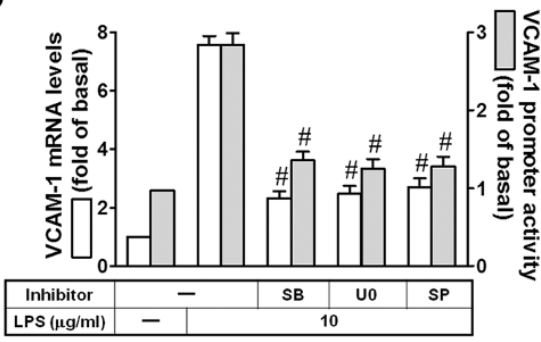

C
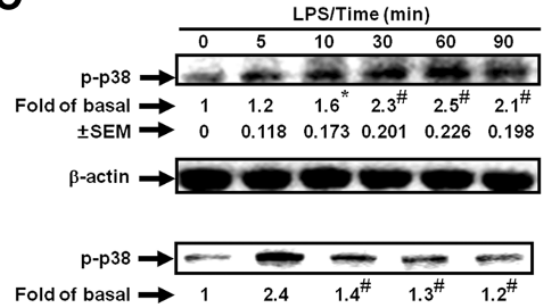

$\pm \mathrm{SEM} \rightarrow \begin{array}{lllll}\rightarrow & 0.238 & 0.133 & 0.115 & 0.113\end{array}$

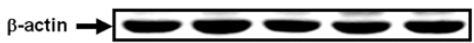

\begin{tabular}{|c|c|c|c|c|c|}
\hline siRNA & - & scrb & c-Src & p44 $7^{\text {phox }}$ & p38 \\
\hline LPS $(\mu \mathrm{g} / \mathrm{ml})$ & - & & & 10 & \\
\hline
\end{tabular}

D

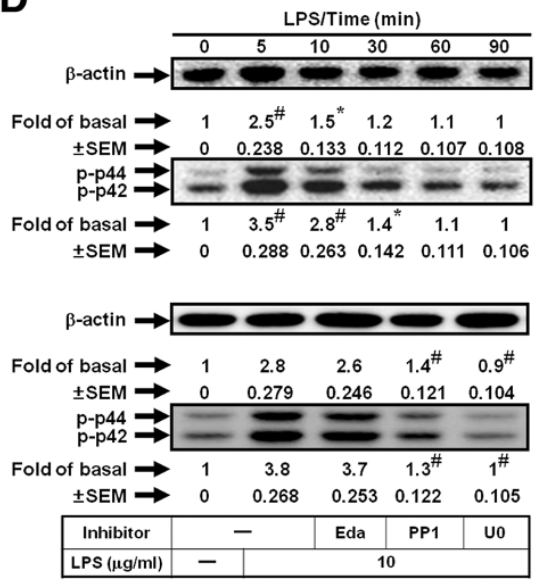

E

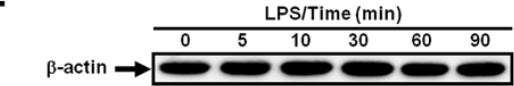

Fold of basal $\rightarrow \begin{array}{llllll}\rightarrow & 1.1 & 1.3 & 1.4^{*} & 1.9^{\#} & 1.1\end{array}$

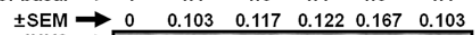
$\mathrm{p}-\mathrm{JNK2} \rightarrow \square-$

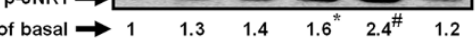

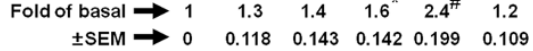
$\beta$-actin $\rightarrow \longrightarrow$

Fold of basal $\rightarrow \begin{array}{llllll}\rightarrow & 1 & 2 & 2.1 & 1^{\#} & 0.8^{\#}\end{array}$ $\pm S E M \rightarrow$
0 $\begin{array}{lllll}0 & 0.193 & 0.197 & 0.113 & 0.107\end{array}$ p-JNK2 $\rightarrow \quad \begin{array}{lllll}0 & 0.193 & 0.197 & 0.113 & 0.107\end{array}$ \begin{tabular}{lllllll}
$\mathrm{P}-\mathrm{JNK1} \rightarrow$ & & & & & & \\
\hline of basal $\rightarrow$ & 1 & 2.5 & 2.6 & $1.2^{\#}$ & $1^{\#}$
\end{tabular}

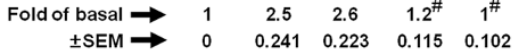

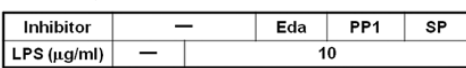

$\mathbf{F}$

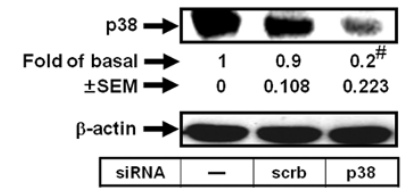

VCAM- $\rightarrow \longrightarrow+1,5$

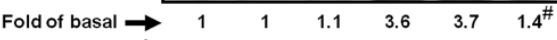

$\pm \mathrm{SEM} \rightarrow \begin{array}{llllll}0 & 0.106 & 0.108 & 0.295 & 0.282 & 1.364\end{array}$

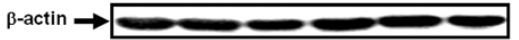

\begin{tabular}{|c|c|c|c|c|c|c|}
\hline SiRNA & - & scrb & p38 & - & scrb & p38 \\
\hline
\end{tabular}

Figure 4 LPS induces VCAM-1 expression via ROS/p38 MAPK. (A) Cells were pretreated with SB202190, U0126, or SP600125, and then incubated with LPS for 8 h. VCAM-1 protein levels were determined. (B) Cells were pretreated with SB202190, U0126, or SP600125, and then incubated with LPS for $4 \mathrm{~h}$ or $6 \mathrm{~h}$. mRNA levels and promoter activity of VCAM-1 were determined. (C) Cells were treated with LPS for the indicated times or transfected with siRNA of c-Src, p47 phox, or p38 MAPK, and then treated with LPS for 1 h. Phospho-p38 MAPK expression was determined. (D) Cells were treated with LPS for the indicated times or pretreated with edaravone (Eda, $100 \mu M)$, PP1 (1 $\mu M)$, or U0126 (U0, $1 \mu M)$, and then treated with LPS for 5 min. Phospho-p42/p44 MAPK expression was determined. (E) Cells were treated with LPS for the indicated times or pretreated with edaravone (Eda), PP1, or SP600125 (SP), and then treated with LPS for 1 h. The expression of phospho-JNK1/2 was determined. (F) Cells were transfected with p38 MAPK siRNA, and then incubated with LPS for $8 \mathrm{~h}$. Protein levels of p38 MAPK and VCAM-1 were determined. All figures are representative of three independent experiments, performed in duplicate. Data are expressed as means \pm SEM. ${ }^{*} P<0.05 ;{ }^{\#} P<0.01$, as compared with the cells exposed to LPS alone (A, B, lower panels of $\mathbf{D}$ and $\mathbf{E}$ ), vehicle alone (upper panels of $\mathbf{C}, \mathbf{D}, \mathbf{E})$, scrambled siRNA alone ( $\mathbf{F}$, upper panel), or LPS + scrambled siRNA (lower panels of $\mathbf{C}$ and $\mathbf{F}$ ). 
A

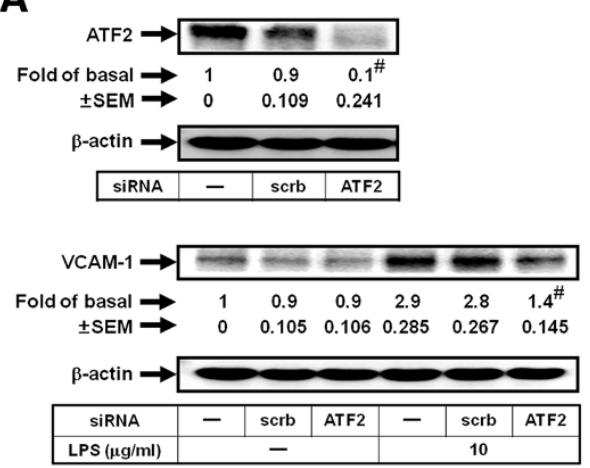

B

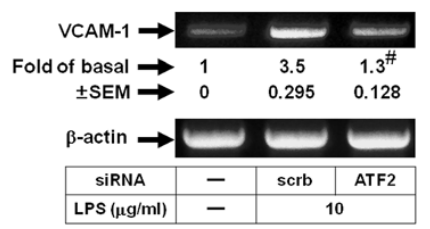

C

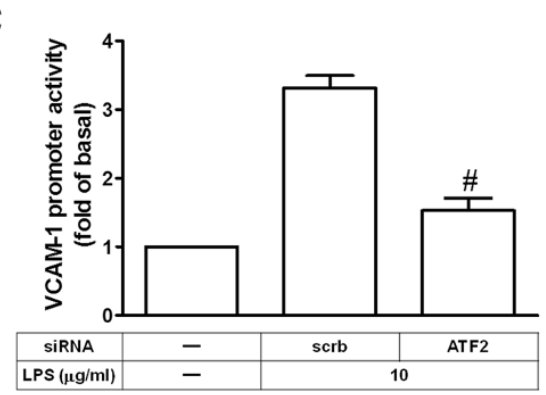

D
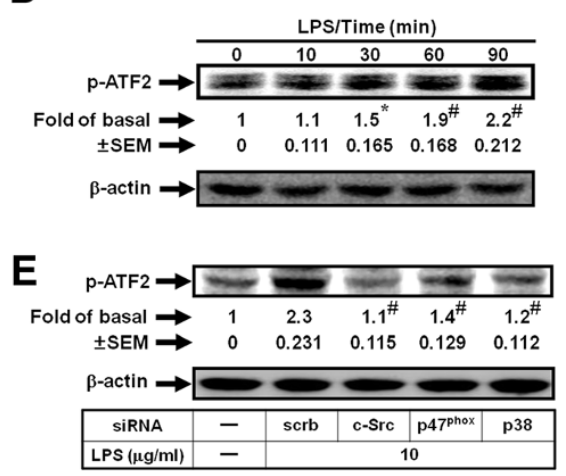

F

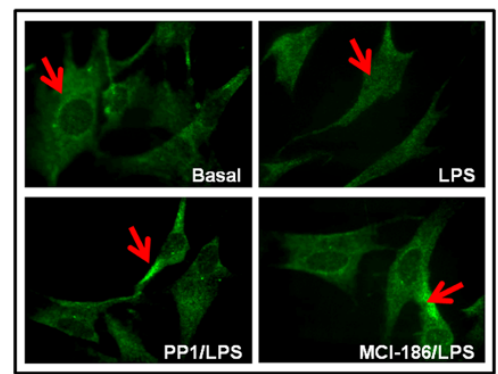

Figure 5 LPS induces VCAM-1 expression via p38 MAPK/ATF2 in HRMCs. Cells were transfected with ATF2 siRNA or scrambled siRNA, and then incubated with LPS for $(\mathbf{A}) 8 \mathrm{~h}$ or $(\mathbf{B}) 4 \mathrm{~h}$. The levels of VCAM-1 protein $(\mathbf{A})$ and mRNA (B) expression were determined. (C) Cells were transiently transfected with VCAM-1-luc reporter gene, transfected with ATF2 siRNA or scrambled siRNA, and then incubated with LPS for 6 h. The VCAM-1 promoter activity was determined. (D) Cells were treated with LPS for the indicated time intervals. The cell lysates were subjected to Western blot using an anti-phospho-ATF2 or anti- $\beta$-actin antibody. (E) Cells were transfected with siRNA of c-Src, p47 ${ }^{\text {phox }}$, p38 MAPK, or scrambled, and then treated with LPS for $90 \mathrm{~min}$. The cell lysates were subjected to Western blot using an anti-phospho-ATF2 or anti- $\beta$-actin antibody. (F) Cells were pretreated with MCl-186 (100 $\mu \mathrm{M})$ or PP1 $(1 \mu \mathrm{M})$ for $1 \mathrm{~h}$, and then treated with LPS for 90 min. Cells were fixed, labeled with an anti-ATF2 antibody, and then FITC-conjugated secondary antibody. Individual cells were imaged. All figures are representative of three independent experiments, performed in duplicate or triplicate. Data are expressed as means \pm SEM. ${ }^{~} P<0.01$, as compared with the cells exposed to scrambled siRNA alone (A, upper panel) or LPS + scrambled siRNA (A, lower panel and $\mathbf{E}) .{ }^{\#} P<0.01$, as compared with the cells exposed to LPS alone $(\mathbf{B}, \mathbf{C}) ;{ }^{*} P<0.05 ;{ }^{\#} P<0.01$, as compared with the cells exposed to vehicle alone (D).

\section{Discussion}

LPS has been shown to stimulate TNF- $\alpha$ production and ICAM-1 and VCAM-1 expression leading to renal inflammatory diseases [3]. LPS-induced VCAM-1 expression has been shown to be mediated through MAPKs, AP-1, and NF- $\mathrm{kB}$ in various cells types [31,32]. It has been reported that NADPH oxidase/ROS generation is necessary for VCAM-1 induction [12]. Thus, these signaling components may regulate VCAM-1 induction in response to LPS in HRMCs. However, the detail mechanisms underlying LPS-induced VCAM-1 expression in HRMCs remain largely unknown. In this study, our results demonstrated that LPS-induced VCAM-1 expression and the adhesion of THP-1 cells to HRMCs were mediated through the p38 MAPK-dependent p300/ATF2 pathway, which was transactivated by a TLR4/MyD88-dependent c$\mathrm{Src} / \mathrm{NADPH}$ oxidase/ROS cascade in these cells (Figure 8).

TLRs are type I transmembrane receptors that expressed on the cell membrane induced by LPS [33]. More than 10 human TLRs have been identified [19]. Moreover, we demonstrated that LPS induced VCAM-1 expression via TLR4 in HRMCs. LPS further directly induced TLR4 gene expression, suggesting that LPS could 


\section{A}

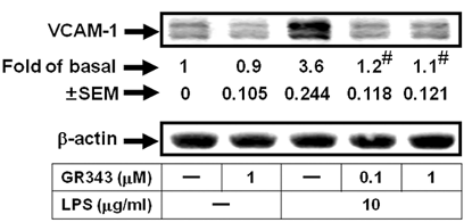

B

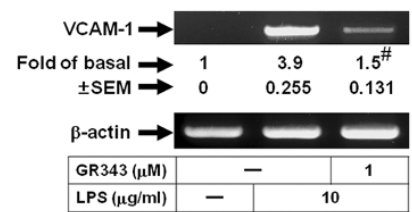

C

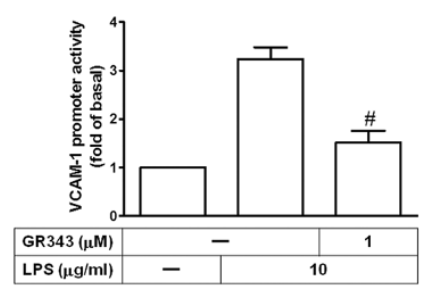

D
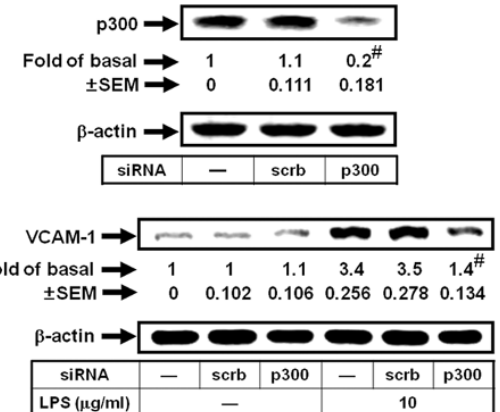

E

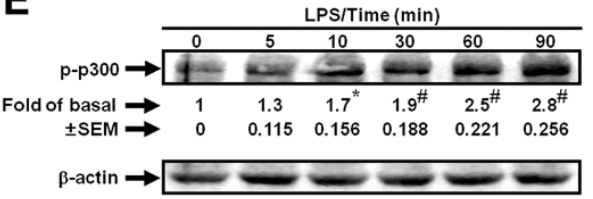

$\mathbf{F}$

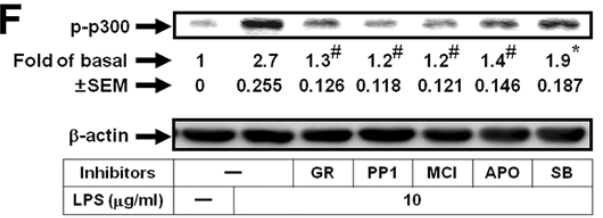

G

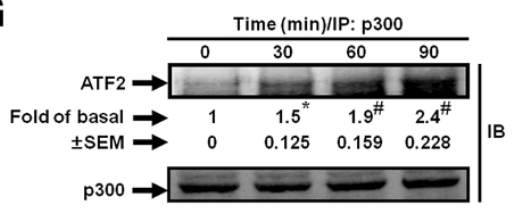

Figure 6 LPS induces VCAM-1 expression via p300. Cells were pretreated with GR343, and then incubated with LPS for (A) 8 h or (B) 4 h. Levels of VCAM-1 protein (A) and mRNA (B) expression were determined. (C) Cells were pretreated with $1 \mu \mathrm{M}$ GR343, and then incubated with LPS for 6 h. VCAM-1 promoter activity was determined. (D) Cells were transfected with p300 siRNA, and then incubated with LPS for 8 h. Protein levels of p300 and VCAM-1 were determined. (E) Cells were treated with LPS for the indicated times. The cell lysates were subjected to Western

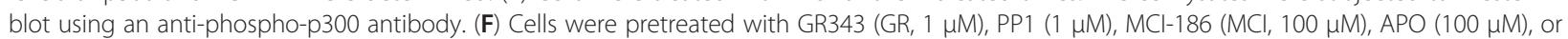
SB202190 (SB, 1 MM), and then treated with LPS for 90 min. The cell lysates were subjected to Western blot using an anti-phospho-p300 antibody. (G) Cells were treated with LPS for the indicated times. The cell lysates were subjected to immunoprecipitation using an anti-p300 antibody, and then the immunoprecipitates were analyzed by Western blot using an anti-ATF2 or anti-p300 antibody. All figures are representative of three independent experiments, performed in duplicate. Data are expressed as means \pm SEM. ${ }^{*} P<0.05 ;{ }^{\sharp} P<0.01$, as compared with the cells exposed to LPS alone (A, B, C, F), scrambled siRNA alone (D, upper panel), LPS + scrambled siRNA (D, lower panel), or vehicle alone (E, G).

stimulate kidney inflammation via TLR4 induction. MyD88 is a cytosolic adapter molecule connecting TLRs and IL-1Rs to the interleukin-1 receptor-associated kinase (IRAK) complex. The MyD88- and IRAK-4-dependent TIR (Toll/IL-1R) pathways lead to the production of proinflammatory cytokines. All human TLRs other than TLR3 use both MyD88 and IRAK-4 to transduce signals [19]. We showed that LPS induced VCAM-1 expression via a TLR4/MyD88-dependent signaling in HRMCs. In the future, we will further investigate whether IRAK-1, IRAK-4, or TRAF6 involves in VCAM-1 induction.

Oxidative stress, induced by systemic and intrarenal generation of ROS can directly exert renal parenchymal damage and may intensify renal microvascular and functional dysregulation, with a feedforward loop of hypoxia and ROS generation. Moreover, ROS have been shown to cause cellular damage or tissue injury, and then mediate the pathogenesis of various renal disorders, such as renal ischemia or nephropathy $[7,10]$. The NADPH oxidase family members are proteins that transfer electrons across biological membranes [9]. In general, the electron acceptor is oxygen and the product of the electron transfer reaction is a superoxide [20]. Therefore, the biological function of NADPH oxidase enzymes might be attributable to the production of ROS [20]. Here, we showed that LPS-induced VCAM-1 expression was inhibited by 

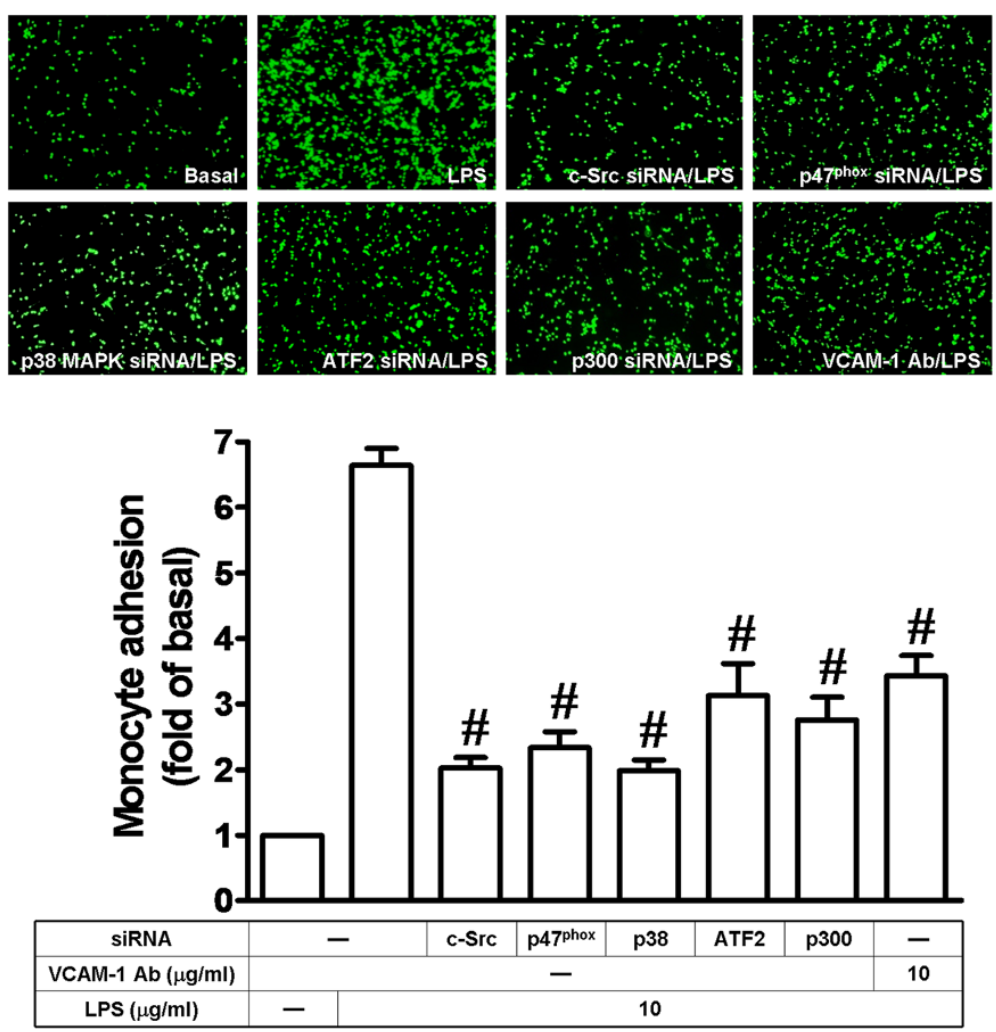

Figure 7 LPS enhances the adhesion of THP-1 cells to HRMCs. Cells were transfected with siRNA of c-Src, p47 ${ }^{\text {phox }}$, p38 MAPK, ATF2, p300 or scrambled, or pretreated with anti-VCAM-1 Ab, and then incubated with LPS for $16 \mathrm{~h}$. The THP-1 cells adherence was measured. All figures are representative of three independent experiments, performed in duplicate. Data are expressed as means \pm SEM. ${ }^{\#} P<0.01$, as compared with the cells exposed to LPS alone.

pretreatment with the inhibitor of NADPH oxidase or a ROS scavenger, suggesting that NADPH oxidase/ROS are involved in LPS-induced inflammatory responses. Activated NADPH oxidase is a multimeric protein complex consisting of at least three cytosolic subunits of $\mathrm{p} 47^{\text {phox }}$, $\mathrm{p} 67^{\text {phox }}$, and $\mathrm{p} 40^{\text {phox }}$. The $\mathrm{p} 47^{\text {phox }}$ regulatory subunit plays a critical role in acute activation of NADPH oxidase; phosphorylation of $\mathrm{p} 47^{\mathrm{phox}}$ is thought to relieve the inhibitory intracellular interactions and permit the binding of $\mathrm{p} 47^{\text {phox }}$ to $\mathrm{p} 22^{\text {phox }}$, thereby increasing oxidase activation $[9,20]$. Moreover, we found that transfection with $\mathrm{p} 47^{\mathrm{phox}}$ siRNA markedly reduced LPS-induced VCAM-1 expression. In addition, LPS also increased the production of $\mathrm{H}_{2} \mathrm{O}_{2}$ and superoxide and the activation of NADPH oxidase in HRMCs. LPS directly stimulated $\mathrm{p} 47^{\text {phox }}$ translocation from the cytosol to the membrane. These results indicated that ROS play a key role in LPS-induced VCAM-1 expression. In renal mesangial cells, Nox1-5 are expressed [34,35]. However, in cultured HRMCs, we only observed that Nox2, Nox4, and Nox5 were expressed (data not shown). Here, we showed that transfection with siRNA of Nox2 or Nox4 markedly reduced LPS-induced VCAM-1 expression in HRMCs. Thus, we suggested that LPS-induced ROS generation was, at least in part, mediated via Nox 2 or Nox4 activation in these cells. In the future, we will investigate the detail mechanisms of LPS-regulated Nox2, Nox4, and Nox5 activation and ROS generation in cultured HRMCs.

Src family kinases are signaling enzymes that have long been recognized to regulate critical cellular processes, such as proliferation, survival, migration, and metastasis [36]. c-Src has been shown to regulate VCAM-1 expression in various cell types $[12,37]$. In addition, NADPH oxidase/ROS have been shown to be mediated through c-Src activation $[9,12]$. We also established that LPS-induced VCAM-1 expression, $\mathrm{p} 47^{\text {phox }}$ translocation, NADPH oxidase activity, and ROS generation was reduced by c-Src inhibition, suggesting that LPS induced VCAM-1 expression via $\mathrm{c}$-Src/NADPH oxidase/ROS in HRMCs. Nox4 was shown to interact with TLR4 and to be required for LPS-induced ROS production [38,39]. It has been shown that Nox2 is required for TLR4-mediated ROS generation [40]. Here, we found that LPS stimulated the formation of TLR4/c-Src/p47 $7^{\text {phox }}$ complex. Therefore, we suggested that LPS could stimulate the protein-protein interactions among TLR4, c-Src, and Nox2 or Nox4, and then increase the generation of ROS. Although the detail proteinprotein interactions among TLR4, c-Src, and $\mathrm{p} 47^{\mathrm{phox}}$ are 


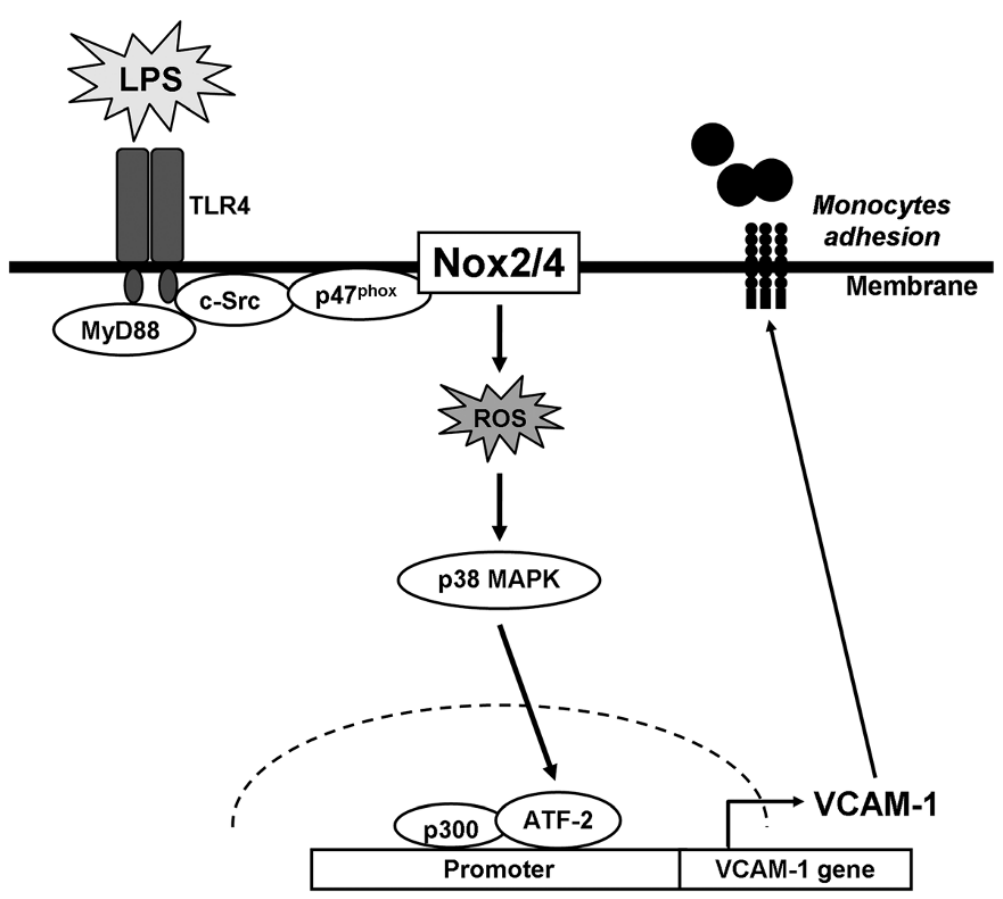

Figure 8 Schematic representation of the signaling pathways involved in the LPS-induced inflammatory responses. LPS induced ROS production through TLR4/MyD88/c-Src/NADPH oxidase, in turn initiates the activation of p38 MAPK and ATF2. Activated ATF2 was recruited to the promoter region of VCAM-1 leading to an increase of VCAM-1 promoter activity and the expression of VCAM-1. Up-regulation of VCAM-1 enhances the adhesion of THP-1 ells to HRMCs challenged with LPS.

not known, our results are the first time to show a novel role of TLR4/MyD88/c-Src/p47 $7^{\text {phox }}$ complex formation in LPS-induced NADPH oxidase activation and ROS production in HRMCs. In the future, we will further determine which domains of TLR4, MyD88, c-Src, and $\mathrm{p} 47^{\text {phox }}$ are involved in protein-protein interactions caused by LPS.

The MAPKs regulate diverse cellular programs by relaying extracellular signals to intracellular responses. In mammals, there are more than a dozen MAPK enzymes that coordinately regulate cell proliferation, differentiation, motility, and survival. The best known are the conventional MAPKs, which include the extracellular signalregulated kinases 1 and 2 (ERK1/2), c-Jun amino-terminal kinases 1 to 3 (JNK1 to -3 ), p38 ( $\alpha, \beta, \gamma$, and $\delta$ ), and ERK5 families [41]. MAPKs also have been shown to regulate VCAM-1 induction [23,25]. Moreover, this is confirmed by our observation that LPS-induced VCAM-1 expression was reduced by inhibition of p38 MAPK, JNK1/2, or p42/ p44 MAPK. ROS have been shown to stimulate p38 MAPK activation [42]. In this study, we demonstrated that LPS-stimulated p38 MAPK, but not p42/p44 MAPK or JNK1/2 activation was mediated through NADPH oxidase/ROS in HRMCs. Thus, we suggested that p38 MAPK mainly plays a key role in LPS-induced NADPH oxidase/ ROS-dependent VCAM-1 expression. AP-1 proteins are implicated in the regulation of various cellular processes including proliferation and survival, differentiation, growth, apoptosis, cell migration, and transformation [43]. AP-1 refers to a mixture of dimers formed between members of the Jun, Fos, and ATF families. Moreover, p38 MAPK has been shown to mediate ATF2 phosphorylation [44]. Here, we showed that LPS markedly induced ATF2 activation, which was reduced by p38 MAPK inhibition. Thus, we demonstrated that LPS induced VCAM-1 expression via ROS/p38 MAPK/ATF2 in HRMCs.

The transcriptional coactivator p300 is a ubiquitous nuclear phosphoprotein and transcriptional cofactor with intrinsic acetyltransferase activity. p300 controls the expression of numerous genes in a cell-type and signal-specific manner, and plays a pivotal role in cellular proliferation, apoptosis, and embryogenesis [45]. By catalyzing acetylation of histones and transcription factors, p300 plays a significant role in epigenetic regulation. Recent evidence suggests that abnormal p300 function is associated with deregulated target gene expression, and is implicated in inflammation $[45,46]$. This is confirmed by our observation that LPS-induced VCAM-1 expression was reduced by inhibition of $\mathrm{p} 300$. Moreover, LPS directly stimulated p300 phosphorylation and the formation of ATF2/p300 complex via c-Src/ROS/p38 MAPK. Taken together, we demonstrated that LPS could trigger renal inflammation via p300-dependent VCAM-1 induction. 


\section{Conclusions}

In summary, as depicted in Figure 8, our results showed that in HRMCs, LPS induced ROS production through TLR4/MyD88/c-Src/Nox2 or Nox4, in turn initiates the activation of p38 MAPK and ATF2. Activated ATF2 was recruited to the promoter region of VCAM-1 leading to an increase of VCAM-1 promoter activity and the expression of VCAM-1. These results provide new insights into the mechanisms of LPS action on HRMCs to regulate the expression of VCAM-1 and thus exaggerated the inflammation responses.

\section{Methods}

\section{Materials}

Anti-VCAM-1, anti-TLR2, anti-TLR4, anti-MyD88, antiNox2, anti-Nox4, anti-p47 ${ }^{\text {phox }}$, anti-Gs $\alpha$, anti-c-Src, anti$\beta$-actin, anti-p38 MAPK, anti-ATF2, and anti-p300 antibodies were from Santa Cruz (Santa Cruz, CA). AntiGAPDH antibody was from Biogenesis (Boumemouth, UK). Anti-phospho-p38 MAPK, anti-phospho-p42/p44 MAPK, anti-phospho-JNK1/2, anti-phospho-c-Src, antiphospho-ATF2, and anti-phospho-p300 antibodies were from Cell Signaling (Danver, MA). Diphenyleneiodonium chloride (DPI), SP600125, U0126, SB202190, GR343, and PP1 were from Biomol (Plymouth Meeting, PA). 5-(and6)-chloromethyl-2,7'-dichlorodihydrofluorescein diacetate, acetyl ester (CM- $\left.\mathrm{H}_{2} \mathrm{DCFDA}\right), 2,7$ '-bis-(2-carboxyethyl)-5(and-6)-carboxyfluorescein, acetoxymethyl ester (BCECF/ AM), and dihydroethidium were from Molecular Probes (Eugene, OR). Edaravone (MCI-186) was from Tocris Bioscience (Ellisville, MO). Apocynin (APO) was purchased from ChromaDex (Santa Ana, CA). LPS, enzymes, and other chemicals were from Sigma (St. Louis, MO).

\section{Cell culture}

Human renal mesangial cells (HRMCs) were from ScienCell Research Laboratories (San Diego, CA). Cells were cultured in DMEM/F12 supplemented with 10\% FBS and antibiotics $(100 \mathrm{U} / \mathrm{ml}$ penicillin $\mathrm{G}, 100 \mu \mathrm{g} / \mathrm{ml}$ streptomycin, and $250 \mathrm{ng} / \mathrm{ml}$ fungizone) at $37^{\circ} \mathrm{C}$ in a humidified $5 \% \mathrm{CO}_{2}$ atmosphere. Experiments were performed with cells from passages 4 to 8 .

\section{Measurement of intracellular ROS accumulation}

The intracellular $\mathrm{H}_{2} \mathrm{O}_{2}$ levels were determined by measuring fluorescence of DCFH-DA, and the $\mathrm{O}_{2}^{--}$levels were determined by measuring the fluorescence of DHE. The fluorescence intensities of DCF and DHE staining were detected at 495/529 and 518/605 nm, respectively, using a fluorescence microscope (Zeiss, Axiovert 200 M). In addition, HRMCs were washed with warm HBSS and incubated in HBSS containing $10 \mu \mathrm{M}$ DCFH-DA or DHE at $37^{\circ} \mathrm{C}$ for $30 \mathrm{~min}$. and then replaced with a fresh medium. HRMCs were incubated with various concentrations of LPS for the indicated time intervals. Cells were washed twice with PBS and detached with trypsin/ EDTA, and the fluorescence intensity of the cells was analyzed using a FACScan flow cytometer (BD Biosciences, San Jose, CA) at $518 \mathrm{~nm}$ excitation and $605 \mathrm{~nm}$ emission for DHE and at 495-nm excitation and $529 \mathrm{~nm}$ emission for DCF.

\section{Determination of NADPH oxidase activity by chemiluminescence assay}

After incubation with LPS, cells were gently scraped and centrifuged at $400 \times g$ for $10 \mathrm{~min}$ at $4^{\circ} \mathrm{C}$. The cell pellet was resuspended with $35 \mu \mathrm{l} /$ per well of ice-cold RPMI1640 medium, and the cell suspension was kept on ice. To a final $200 \mu \mathrm{l}$ volume of pre-warmed $\left(37^{\circ} \mathrm{C}\right) \mathrm{RPMI}-1640$ medium containing either NADPH $(1 \mu \mathrm{M})$ or lucigenin $(20 \mu \mathrm{M}), 5 \mu \mathrm{l}$ of cell suspension $\left(0.2 \times 10^{5}\right.$ cells $)$ was added to initiate the reaction followed by immediate measurement of chemiluminescence in an Appliskan luminometer $\left(\right.$ Thermo $\left.^{\circledR}\right)$ in an out-of-coincidence mode. Appropriate blanks and controls were established, and chemiluminescence was recorded. Neither NADPH nor NADH enhanced the background chemiluminescence of lucigenin alone (30-40 counts per min). Chemiluminescence was continuously measured for $12 \mathrm{~min}$, and the activity of $\mathrm{NADPH}$ oxidase was expressed as counts per million cells.

\section{Western blot analysis}

Growth-arrested cells were incubated with LPS at $37^{\circ} \mathrm{C}$ for the indicated time intervals. The cells were washed, scraped, collected, and centrifuged at $45000 \times g$ at $4{ }^{\circ} \mathrm{C}$ for $1 \mathrm{~h}$ to yield the whole cell extract, as previously described [9]. Samples were denatured, subjected to SDS-PAGE using a $12 \%$ running gel, and transferred to nitrocellulose membrane. Membranes were incubated with an antiVCAM-1 antibody for $24 \mathrm{~h}$, and then incubated with an anti-mouse horseradish peroxidase antibody for $1 \mathrm{~h}$. The immunoreactive bands were detected by ECL reagents.

\section{RT-PCR analysis}

Total RNA was isolated with Trizol according to the protocol of the manufacturer. The cDNA obtained from $0.5 \mu \mathrm{g}$ total RNA was used as a template for PCR amplification as previously described [9]. The primers used were as follows: 5'-TGACGGGGTCACCCAC ACTGTGCCCATCTA-3' (sense) and 5'-CTAGAAG CATTTGCGGTGGACGATG-3' (anti-sense) for $\beta$-actin; 5'-GGAACCTTGCAGCTTACAGTGACAGAGCTCCC-3' (sense) 5'-CAAGTCTACATATCACCCAAG-3' (anti-sense) for VCAM-1; and ;5'-TGGATACGTTTCCTTATAAG-3' (sense) and 5'-GAAATGGAGGCACCCCTTC-3' (antisense) for TLR4. 


\section{Real-time RT-PCR analysis}

Total RNA was extracted using TRIzol reagent. mRNA was reverse-transcribed into cDNA and analyzed by realtime RT-PCR. Real-time PCR was performed using SYBR Green PCR reagents (Applied Biosystems, Branchburg, $\mathrm{NJ}$ ) and primers specific for VCAM-1 and GAPDH mRNAs. The levels of VCAM-1 expression were determined by normalizing to GAPDH expression.

\section{Transient transfection with siRNAs}

The small interfering RNA (siRNA) duplexes corresponding to human Nox2, Nox4, TLR2, TLR4, MyD88, p47 $7^{\text {phox }}$, c-Src, p38 MAPK, ATF2, and p300 and scrambled siRNA were from Invitrogen (Carlsbad, CA). Transient transfection of siRNAs was carried out using Metafectene transfection reagent from Biontex Lab (GmbH, Planegg/ Martinsried, Germany). siRNA (100 nM) was formulated with Metafectene transfection reagent according to the manufacturer's instruction.

\section{Isolation of cell fractions}

Cells were harvested, sonicated for $5 \mathrm{~s}$ at output 1.5 with a sonicator (Misonix Inc., Farmingdale, NY), and centrifuged at $8000 \mathrm{rpm}$ for $15 \mathrm{~min}$ at $4^{\circ} \mathrm{C}$. The pellet was collected as the nuclear fraction. The supernatant was centrifuged at $14000 \mathrm{rpm}$ at $4^{\circ} \mathrm{C}$ for $60 \mathrm{~min}$ to yield the pellet (membrane fraction) and the supernatant (cytosolic fraction).

\section{Measurement of VCAM-1 luciferase activity}

For construction of the VCAM-1-luc plasmid, human VCAM-1 promoter, a region spanning -1716 to $-119 \mathrm{bp}$ (kindly provided by Dr. W.C. Aird, Department of Molecular Medicine, Beth Israel Deaconess Medical Center, Boston, MA) was cloned into pGL3-basic vector (Promega, Madison, WI). VCAM-1-luc activity was determined using a luciferase assay system, as previously described [25] (Promega, Madison, WI).

\section{Adhesion assay}

HRMCs were grown to confluence in 6-well plates with coverslips, incubated with LPS for $16 \mathrm{~h}$, and then adhesion assays were performed. Briefly, THP-1 cells (human acute monocytic leukemia cell line) were labeled with a fluorescent dye, $10 \mu \mathrm{M} \mathrm{BCECF/AM}$, at $37^{\circ} \mathrm{C}$ for $1 \mathrm{~h}$ in RPMI-1640 medium (Gibco BRL, Grand Island, NY) and subsequently washed with PBS followed by centrifugation. Confluent HRMCs in 6-well plates were incubated with THP- 1 cells $\left(2 \times 10^{6}\right.$ cells $\left./ \mathrm{ml}\right)$ at $37^{\circ} \mathrm{C}$ for $1 \mathrm{~h}$. Nonadherent THP-1 cells were removed and plates were gently washed twice with PBS. The numbers of adherent THP-1 cells were determined by counting four fields per 200X high-power field well using a fluorescence microscope (Zeiss, Axiovert $200 \mathrm{M}$ ). Experiments were performed in triplicate and repeated at least three times.

\section{Co-immunoprecipitation assay}

Cell lysates containing $1 \mathrm{mg}$ of protein were incubated with $2 \mu \mathrm{g}$ of an anti-c-Src or anti-p300 antibody at $4^{\circ} \mathrm{C}$ for $24 \mathrm{~h}$, and then $10 \mu \mathrm{l}$ of $50 \%$ protein $\mathrm{A}$-agarose beads was added and mixed at $4^{\circ} \mathrm{C}$ for $24 \mathrm{~h}$. The immunoprecipitates were collected and washed thrice with a lysis buffer without Triton X-100. 5X Laemmli buffer was added and subjected to electrophoresis on SDS-PAGE, and then blotted using an anti-TLR4, anti-p47 ${ }^{\text {phox }}$, anti-c-Src, anti-p300, or anti-ATF2 antibody.

\section{Analysis of data}

Data were estimated using a GraphPad Prism Program (GraphPad, San Diego, CA). Quantitative data were expressed as the means \pm SEM and analyzed by one-way ANOVA followed with Tukey's post-hoc test. $P<0.05$ was considered significant.

\section{Abbreviations}

AP-1: Activator protein-1; HRMCs: Human renal mesangial cells; LPS: Lipopolysaccharide; MCs: Mesangial cells; NADPH: Nicotinamide adenine dinucleotide phosphate; ROS: Reactive oxygen species; TLRs: Toll-like receptors; VCAM-1: Vascular cell adhesion molecule-1.

\section{Competing interests}

The authors declare that they have no competing interests.

\section{Author's contributions}

ITL and RHS designed and performed experiments, acquisition and analysis of data, and drafted the manuscript. CCL and JTC helped to perform experiments and prepare the manuscript. CMY has conceived of the study, participated in its design and coordination, has been involved in drafting the manuscript and revising it critically for important intellectual content and has given final approval of the version to be published. All authors have read and approved the final version of this manuscript.

\section{Acknowledgements}

This work was supported by NSC101-2314-B-182A-112, NSC98-2321-B-182004, NSC99-2321-B-182-003, NSC98-2320-B-182-004-MY3, and NSC98-2314-B 182-021-MY3, from National Science Council, Taiwan; EMRPD1B0311 and EMRPD1B0321 from Ministry of Education, Taiwan; and CMRPG391032. CMRPG381522, CMRPD170493, CMRPD180373, CMRPD1A0151, CMRPD1B0381, and CMRPG3B1091 from Chang Gung Medical Research Foundation, Taiwan

\section{Author details}

${ }^{1}$ Department of Anesthetics, Chang Gung Memorial Hospital at Linkou and College of Medicine, Chang Gung University, Kwei-San, Tao-Yuan, Taiwan. ${ }^{2}$ Department of Physiology and Pharmacology and Health Aging Research Center, College of Medicine, Chang Gung University, 259 Wen-Hwa 1st Road, Kwei-San, Tao-Yuan, Taiwan.

Received: 10 August 2012 Accepted: 12 November 2012 Published: 15 November 2012

\section{References}

1. Masuya M, Drake CJ, Fleming PA, Reilly CM, Zeng H, Hill WD, MartinStuddard A, Hess DC, Ogawa M: Hematopoietic origin of glomerular mesangial cells. Blood 2003, 101:2215-2218.

2. Gomez-Guerrero C, Hernandez-Vargas P, Lopez-Franco O, Ortiz-Munoz G, Egido J: Mesangial cells and glomerular inflammation: from the 
pathogenesis to novel therapeutic approaches. Curr Drug Targets Inflamm Allergy 2005, 4:341-351.

3. Baran D, Vendeville B, Ogborn M, Katz N: Cell adhesion molecule expression in murine lupus-like nephritis induced by lipopolysaccharide. Nephron 2000, 84:167-176

4. Patole PS, Pawar RD, Lech M, Zecher D, Schmidt H, Segerer S, Ellwart A, Henger A, Kretzler M, Anders HJ: Expression and regulation of Toll-like receptors in lupus-like immune complex glomerulonephritis of MRL-Fas (Ipr) mice. Nephrol Dial Transplant 2006, 21:3062-3073.

5. Schwartz DA, Cook DN: Polymorphisms of the Toll-like receptors and human disease. Clin Infect Dis 2005, 41(Suppl 7):S403-S407.

6. Cardinal JS, Zhan J, Wang Y, Sugimoto R, Tsung A, McCurry KR, Billiar TR, Nakao A: Oral hydrogen water prevents chronic allograft nephropathy in rats. Kidney Int 2010, 77:101-109.

7. Kim J, Jang HS, Park KM: Reactive oxygen species generated by renal ischemia and reperfusion trigger protection against subsequent renal ischemia and reperfusion injury in mice. Am J Physiol Renal Physiol 2010, 298:F158-F166.

8. Bondi CD, Manickam N, Lee DY, Block K, Gorin Y, Abboud HE, Barnes JL: $\mathrm{NAD}(\mathrm{P}) \mathrm{H}$ oxidase mediates TGF- $\beta 1$-induced activation of kidney myofibroblasts. J Am Soc Nephrol 2010, 21:93-102

9. Lee IT, Wang SW, Lee CW, Chang CC, Lin CC, Luo SF, Yang CM: Lipoteichoic acid induces HO-1 expression via the TLR2/MyD88/c-Src/NADPH oxidase pathway and Nrf2 in human tracheal smooth muscle cells. J Immunol 2008, 181:5098-5110

10. Chen Y, Zhang AH, Huang SM, Ding GX, Zhang WZ, Bao HY, Wu HM, Chen $\mathrm{RH}$ : [NADPH oxidase-derived reactive oxygen species involved in angiotensin II-induced monocyte chemoattractant protein-1 expression in mesangial cells]. Zhonghua Bing Li Xue Za Zhi 2009, 38:456-461.

11. Chen J, Tang H, Hay N, Xu J, Ye RD: Akt isoforms differentially regulate neutrophil functions. Blood 2010, 115:4237-4246.

12. Luo SF, Chang CC, Lee IT, Lee CW, Lin WN, Lin CC, Yang CM: Activation of ROS/NF-KB and $\mathrm{Ca}^{2+} / \mathrm{CaM}$ kinase II are necessary for VCAM-1 induction in IL-1 $\beta$-treated human tracheal smooth muscle cells. Toxicol Appl Pharmacol 2009, 237:8-21.

13. Chowdhury AK, Watkins T, Parinandi NL, Saatian B, Kleinberg ME, Usatyuk PV, Natarajan V: Src-mediated tyrosine phosphorylation of $\mathrm{p} 47^{\text {phox }}$ in hyperoxia-induced activation of NADPH oxidase and generation of reactive oxygen species in lung endothelial cells. J Biol Chem 2005, 280:20700-20711.

14. Kwon CH, Park JY, Kim TH, Woo JS, Kim YK: Ciglitazone induces apoptosis via activation of p38 MAPK and AIF nuclear translocation mediated by reactive oxygen species and $\mathrm{Ca}^{2+}$ in opossum kidney cells. Toxicology 2009, 257:1-9.

15. lademarco MF, McQuillan JJ, Rosen GD, Dean DC: Characterization of the promoter for vascular cell adhesion molecule-1 (VCAM-1). J Biol Chem 1992, 267:16323-16329.

16. De BK, Vanden BW, Haegeman G: The interplay between the glucocorticoid receptor and nuclear factor-кB or activator protein-1: molecular mechanisms for gene repression. Endocr Rev 2003, 24:488-522.

17. Shaulian E, Karin M: AP-1 as a regulator of cell life and death. Nat Cell Biol 2002, 4:E131-E136

18. Lin WN, Lin CC, Cheng HY, Yang CM: Regulation of cyclooxygenase-2 and cytosolic phospholipase $A_{2}$ gene expression by lipopolysaccharide through the RNA-binding protein HuR: involvement of NADPH oxidase, reactive oxygen species and mitogen-activated protein kinases. Br J Pharmacol 2011, 163:1691-1706.

19. Essakalli M, Atouf O, Bennani N, Benseffaj N, Ouadghiri S, Brick C: [Toll-like receptors]. Pathol Biol (Paris) 2009, 57:430-438

20. Lee IT, Luo SF, Lee CW, Wang SW, Lin CC, Chang CC, Chen YL, Chau LY, Yang CM: Overexpression of HO-1 protects against TNF-a-mediated airway inflammation by down-regulation of TNFR1-dependent oxidative stress. Am J Pathol 2009, 175:519-532

21. Liu A, Gong P, Hyun SW, Wang KZ, Cates EA, Perkins D, Bannerman DD, Puche AC, Toshchakov VY, Fang S, Auron PE, Vogel SN, Goldblum SE: TRAF6 protein couples Toll-like receptor 4 signaling to Src family kinase activation and opening of paracellular pathway in human lung microvascular endothelia. J Biol Chem 2012, 287:16132-16145.

22. Gong P, Angelini DJ, Yang S, Xia G, Cross AS, Mann D, Bannerman DD, Vogel SN, Goldblum SE: TLR4 signaling is coupled to SRC family kinase activation, tyrosine phosphorylation of zonula adherens proteins, and opening of the paracellular pathway in human lung microvascular endothelia. J Biol Chem 2008, 283:13437-13449.

23. Byeon HE, Um SH, Yim JH, Lee HK, Pyo S: Ohioensin F suppresses TNF-ainduced adhesion molecule expression by inactivation of the MAPK, Akt and NF-KB pathways in vascular smooth muscle cells. Life Sci 2012, 90:396-406.

24. Hsu WY, Chao YW, Tsai YL, Lien CC, Chang CF, Deng MC, Ho LT, Kwok CF, Juan CC: Resistin induces monocyte-endothelial cell adhesion by increasing ICAM-1 and VCAM-1 expression in endothelial cells via p38MAPK-dependent pathway. J Cell Physiol 2011, 226:2181-2188.

25. Lee CW, Lin WN, Lin CC, Luo SF, Wang JS, Pouyssegur J, Yang CM: Transcriptional regulation of VCAM-1 expression by tumor necrosis factor- $a$ in human tracheal smooth muscle cells: involvement of MAPKs, NF-kB, p300, and histone acetylation. J Cell Physiol 2006, 207:174-186.

26. Liu CM, Sun YZ, Sun JM, Ma JQ, Cheng C: Protective role of quercetin against lead-induced inflammatory response in rat kidney through the ROS-mediated MAPKs and NF-kB pathway. Biochim Biophys Acta 2012, 1820:1693-1703.

27. Yang CM, Lin CC, Lee IT, Lin YH, Yang CM, Chen WJ, Jou MJ, Hsiao LD: Japanese encephalitis virus induces matrix metalloproteinase-9 expression via a ROS/c-Src/PDGFR/PI3K/Akt/MAPKs-dependent AP-1 pathway in rat brain astrocytes. J Neuroinflammation 2012, 9:12.

28. Yu M, Zheng Y, Sun HX, Yu DJ: Inhibitory effects of enalaprilat on rat cardiac fibroblast proliferation via ROS/P38MAPK/TGF- $\beta 1$ signaling pathway. Molecules 2012, 17:2738-2751

29. Lee SH, Bahn JH, Whitlock NC, Baek SJ: Activating transcription factor 2 (ATF2) controls tolfenamic acid-induced ATF3 expression via MAP kinase pathways. Oncogene 2010, 29:5182-5192.

30. Reimold AM, Kim J, Finberg R, Glimcher LH: Decreased immediate inflammatory gene induction in activating transcription factor-2 mutant mice. Int Immunol 2001, 13:241-248.

31. Chen R, Alvero AB, Silasi DA, Steffensen KD, Mor G: Cancers take their Tollthe function and regulation of Toll-like receptors in cancer cells. Oncogene 2008, 27:225-233.

32. Chen K, Huang J, Gong W, Iribarren P, Dunlop NM, Wang JM: Toll-like receptors in inflammation, infection and cancer. Int Immunopharmaco 2007, 7:1271-1285

33. Hedayat M, Netea MG, Rezaei N: Targeting of Toll-like receptors: a decade of progress in combating infectious diseases. Lancet Infect Dis 2011, 11:702-712.

34. Block K, Eid A, Griendling KK, Lee DY, Wittrant Y, Gorin Y: Nox4 NAD(P)H oxidase mediates Src-dependent tyrosine phosphorylation of PDK-1 in response to angiotensin II: role in mesangial cell hypertrophy and fibronectin expression. J Biol Chem 2008, 283:24061-24076.

35. Kaysen GA, Eiserich JP: The role of oxidative stress-altered lipoprotein structure and function and microinflammation on cardiovascular risk in patients with minor renal dysfunction. J Am Soc Nephrol 2004, 15:538-548.

36. Kim MP, Park SI, Kopetz S, Gallick GE: Src family kinases as mediators of endothelial permeability: effects on inflammation and metastasis. Cell Tissue Res 2009, 335:249-259.

37. Baek JE, Yang WS, Chang JW, Kim SB, Park SK, Park JS, Lee SK: Fatty acidbearing albumin induces VCAM-1 expression through c-Src kinase-AP-1/ NF-KB pathways: effect of L-carnitine. Kidney Blood Press Res 2010, 33:72-84.

38. Ben MS, Pedruzzi E, Werts C, Coant N, Bens M, Cluzeaud F, Goujon JM, Ogier-Denis E, Vandewalle A: Heat shock protein gp96 and $\mathrm{NAD}(\mathrm{P}) \mathrm{H}$ oxidase 4 play key roles in Toll-like receptor 4-activated apoptosis during renal ischemia/reperfusion injury. Cell Death Differ 2010, 17:1474-1485

39. Park HS, Jung HY, Park EY, Kim J, Lee WJ, Bae YS: Cutting edge: direct interaction of TLR4 with NAD(P)H oxidase 4 isozyme is essential for lipopolysaccharide-induced production of reactive oxygen species and activation of NF-kB. J Immunol 2004, 173:3589-3593.

40. Bae YS, Lee JH, Choi SH, Kim S, Almazan F, Witztum JL, Miller Yl: Macrophages generate reactive oxygen species in response to minimally oxidized low-density lipoprotein: toll-like receptor 4- and spleen tyrosine kinase-dependent activation of NADPH oxidase 2. Circ Res 2009, 104:210-218.

41. Cargnello M, Roux PP: Activation and function of the MAPKs and their substrates, the MAPK-activated protein kinases. Microbiol Mol Biol Rev 2011, 75:50-83. 
42. Matsuzawa A, Saegusa K, Noguchi T, Sadamitsu C, Nishitoh H, Nagai S, Koyasu S, Matsumoto K, Takeda K, Ichijo H: ROS-dependent activation of the TRAF6-ASK1-p38 pathway is selectively required for TLR4-mediated innate immunity. Nat Immunol 2005, 6:587-592.

43. Vesely PW, Staber PB, Hoefler G, Kenner L: Translational regulation mechanisms of AP-1 proteins. Mutat Res 2009, 682:7-12.

44. Kole L, Giri B, Manna SK, Pal B, Ghosh S: Biochanin-A, an isoflavon, showed anti-proliferative and anti-inflammatory activities through the inhibition of iNOS expression, p38-MAPK and ATF-2 phosphorylation and blocking NF-KB nuclear translocation. Eur J Pharmacol 2011, 653:8-15.

45. Vanden BW, Vermeulen L, Delerive P, De BK, Staels B, Haegeman G: A paradigm for gene regulation: inflammation, NF-KB and PPAR. Adv Exp Med Biol 2003, 544:181-196.

46. Escobar J, Pereda J, Arduini A, Sandoval J, Sabater L, Aparisi L, Vento M, Lopez-Rodas G, Sastre J: Role of redox signaling, protein phosphatases and histone acetylation in the inflammatory cascade in acute pancreatitis. Therapeutic implications. Inflamm Allergy Drug Targets 2010, 9:97-108.

doi:10.1186/1478-811X-10-33

Cite this article as: Lee et al:: Role of TLR4/NADPH oxidase/

ROS-activated p38 MAPK in VCAM-1 expression induced by

lipopolysaccharide in human renal mesangial cells. Cell Communication

and Signaling 2012 10:33

\section{Submit your next manuscript to BioMed Central and take full advantage of:}

- Convenient online submission

- Thorough peer review

- No space constraints or color figure charges

- Immediate publication on acceptance

- Inclusion in PubMed, CAS, Scopus and Google Scholar

- Research which is freely available for redistribution 